\title{
Qualitative research between craftsmanship and McDonaldization. A keynote address from the 17th Qualitative Health Research Conference ${ }^{1}$
}

\author{
Svend Brinkmann
}

\begin{abstract}
Although qualitative research methods remain marginalized in certain disciplines, qualitative inquiry has within the last couple of decades become generally accepted as a legitimate scientific way of working. Today, society at large is making more use of qualitative research than ever, not just in laudable social justice research, for example, but also in relation to market and consumer research and focus groups for different political parties. With this in mind, I wish to discuss three current questions for qualitative researchers: The first I will refer to as "ethical progressivism versus new ethical challenges". Is qualitative research as such more ethical and progressive than quantitative research (as some have argued), or do qualitative researchers on the contrary face more elusive and perhaps difficult ethical challenges? The second question is called "solid evidence versus subjective anecdotes". How should qualitative researchers respond to the current call for evidence? Should they seek legitimacy by accepting the dominant politics of evidence, or should they play by their own rules with the risk of increasing marginalization? The third question is "method versus intuition". Should qualitative researchers strive for maximum transparency by following accepted methods, or should they proceed more intuitively like artists to create their stories? Both sides of the questions have their influential advocates today. I will argue that all three questions are handled most fruitfully by conceiving of qualitative research as a craft.
\end{abstract}

Keywords: challenges to qualitative research; McDonaldization; craftsmanship; consumer society

Please cite this article as:

Brinkmann, S. (2012). Qualitative research between craftsmanship and McDonaldization. A keynote address from the 17th Qualitative Health Research Conference. Qualitative Studies, 3(1): 56-68.

\section{Introduction}

Let me begin by thanking the International Institute of Qualitative Methodology and the organizers of this conference for inviting me to come all the way to Canada, this very beautiful country, and to Vancouver, this most welcoming city. It is a pleasure to be here, and I have learned a lot from being here this week. My talk today will be about current questions in qualitative research, as we are situated in the specific cultural historical situation that I will address as consumer society.

Qualitative researchers have been excellent at providing analyses of how knowledge is produced and circulate in society. This endeavour is often called "the sociology of knowledge", but what they - or we - have been less good at, is directing the tools of sociology of knowledge to qualitative research itself. This is what I will do in my talk. I will argue that we need to

\footnotetext{
${ }^{1}$ This paper is an edited, revised and expanded version of a keynote address that was given at the 17th Qualitative Health Research Conference in Vancouver, Canada, on October 26, 2011. I have kept the speech format of the text in order to maintain the tentative and oral nature of the argument.
} 
understand qualitative research as situated in a specific historical situation, and that this presents us with a number of challenges. Some of my remarks may be controversial, since they are likely to interfere with the established self-understandings of some qualitative researchers: That we are ethically good, because we are qualitative, that positivism is pure evil and that we need methods of inquiry in order to be scientific. I should add that I am not certain that all my ideas will stand the test of intellectual scrutiny, but I allow myself nonetheless to present them to you for discussion.

As you know, the theme of the congress is "Research for change: Impacting society through qualitative research". Very often qualitative researchers complain that what they do does not have an impact. "We don't count, because we don't count!" is the message articulated by many people in qualitative research. This means we don't count, because we don't have numbers. Often, when qualitative researchers feel that their research is ignored, they explain this by pointing to their methods of inquiry as not being sufficiently recognized. I am not saying that this is a complete misunderstanding, but I often have problems recognizing this state of affair. This is so, mainly because I find that qualitative research in fact has a huge impact on modern society (perhaps sometimes too huge!), and I am going to return to this in a short while.

Here, I might add that within my own field of psychology such giants as Sigmund Freud on psychoanalysis, Wilhelm Wundt on anthropological psychology, Jean Piaget on children's development and Frederick Bartlett on remembering do in fact count as some of the most influential founding fathers of the discipline, who all did what we now call qualitative research (see Brinkmann \& Kvale, 2005). Some of them have also had quite an impact on modern society, particularly Freud. Interestingly, these scholars found no need to designate their methods of inquiry with the label "qualitative"; they just did science and used whatever investigative tool they found adequate. In passing, I may also add that natural scientists do exactly the same thing, and often work qualitatively, e.g. in anatomy, chemistry and biology, all of which are inconceivable without basic qualitative frameworks (Kvale \& Brinkmann, 2008). But this is a topic for a quite different talk.

Another thing is that people who do quantitative research in psychology, social science, and, I suspect, health, very often have the exact same feeling: "No one is listening to me, no one shares my enthusiasm for this fantastic result that I have come up with - alas, my research is not having the societal impact I had hoped for!" Perhaps there is not with respect to this problem much of a difference between qualitative and quantitative research. In the current marketplace of research, with an ever-growing amount of commodified "knowledge" (which I think we often need to put in quotation marks), it is simply just difficult to be heard and have one's research make an impact on society. As I see it, qualitative researchers should avoid marginalizing themselves by constantly reinforcing the story that no one wants to listen to them in particular. Actually, the case studies done by qualitative researchers are often discussed in public and stay on people's minds, sometimes much more than impersonal statistics.

In the rest of my talk today, I will do three things: First, I will address the role of qualitative research in modern society. I will try to tell a story that is different from the common one of marginalization. Second, I will sketch three questions in current qualitative research that relate to its current cultural status. Finally, I will present an approach to qualitative research as a craft, which is meant to resolve some of the questions and also enable us to better understand the societal role of qualitative research - and judge its contemporary impact. In particular I will warn against what I shall refer to as the current McDonaldization of qualitative research. 


\section{Qualitative research in modern society}

It has become rather trivial to say that modern society - at least in the imagined hemisphere we call the West - is a consumer society (Paterson, 2006). Very often, however, we (including culturally sensitive qualitative researchers) forget to take the societal situation of our work into account. What is consumer society and how does qualitative research relate to this?

One way to approach an answer is to draw a contrast with industrial society. Henry Ford, inventor of the assembly line production, incarnated the logic of industrial society with his wellknown remark that customers could have the Ford T in any colour they wanted, as long as they wanted black (Paterson, 2006, p. 61). Industrial society was built on this logic of production: Products should be as cheap and reliable as possible, and new means of mass production were able to help the companies produce the standardised commodities to the consumers. However, a significant change of focus took place in the years following World War II. Henry Ford's dictum became totally outdated in the affluent societies that emerged in the West, not least with the rise of the countercultures of the 60s and 70s. Along with increased wealth and mobility came the need to make more life choices (Honneth, 2004). Today, we have no choice but to choose, as Anthony Giddens (1991, p. 81) has elegantly put it, even if the experience of choice is often illusory for individuals in the lower strata of society. And there remain few places to look for a guide to make life choices outside the individual's own self. It thus became imperative to 'know one's self', and self-realization has become part of the institutionalised expectations inherent in the social reproduction of society, as the German philosopher Axel Honneth has argued (Honneth, 2004, p. 463).

Obviously, there has been what we now call qualitative research prior to the advent of consumer society, but I think there is a non-accidental link between the rise of this kind of society and the boom in qualitative inquiry that we have witnessed in the last fifty years or so. On my interpretation, this is due not least to the fact that contemporary capitalism has become experiential or emotional, to borrow the title of Eva Illouz' wonderful book on Cold Intimacies: The Making of Emotional Capitalism (Illouz, 2007). Consumer society is an experience society, as the German sociologist Gerhard Schulze (1992) has argued. The main commodity today has become experiencing itself, which is nowhere more visible than in the fact that tourism has become one of the world's largest industries, if not the largest.

Zygmunt Bauman has aptly captured this change with his well-known identity metaphors, the pilgrim and the tourist (Bauman, 1996). The pilgrim travelled to a fixed destination that was of value in independence of the pilgrim's own experiences and preferences. The destination was a sacred place, because it had somehow been endowed with divine force. Today's tourist, on the other hand, travels only in order to find new, pleasurable experiences. Tourism is first and foremost an aesthetic practice and it is a practice that demands constant change, for: "You can't have a favorite place until you've seen them all!", as the Intercontinental Hotel ad says... Advertising is the poetry of capitalism that harbours deep truths about our current selfunderstandings. We live in an era where everyone's narratives, experiences and opinions are interesting and circulate as commodities. With specific reference to qualitative interviewing, which is my own main area, Atkinson \& Silverman (1997) referred fifteen years ago to our society as an interview society, in which the self is continually produced in confessional settings ranging from talk shows to research interviews. They find that "in promoting a particular view of narratives of personal experience, researchers too often recapitulate, in an uncritical fashion, 
features of the contemporary interview society" where "the interview becomes a personal confessional" (p. 305).

In consumer society, softer, and more concealed, forms of power gradually replace the bureaucratic structures of industrial society with its visible hierarchies and governance through reward and punishment. A chief technique of governance today, as Nikolas Rose has demonstrated, is management through subtle and soft quasi-therapeutic techniques (Rose, 1999).

Analogously, and this is where my argument might get controversial, in consumer society, soft qualitative research has been added to the repertoire of scientific methodology, often superseding the bureaucratic forms of data collection in standardized surveys and quantitative experiments that reflected the hard power exertion in more hierarchical societies. While a textbook on quantitative methodology may read like a manual for administrators and engineers, interested in rationalization and time-and-motion studies, qualitative guidebooks read more like manuals for personnel coaches and advertisers, interested in personal potential and desire.

We should not, I believe, overlook the immersion of qualitative research in a consumer society, with its sensitivity towards experiences, images, feelings and lifestyles of the consumers. Focus groups and qualitative interviews in particular have been used to generate knowledge to manipulate consumers' desires and behaviors through psychologically sophisticated advertising. One of the most significant methods of marketing in consumer society is thus unsurprisingly qualitative market research. It accounts for an enormous global turnover (Imms \& Ereaut, 2002), and, according to one serious estimate, $5 \%$ of all British adults have taken part in market research focus groups. Talk about a powerful research methodology that makes an impact!

I believe it is relevant to raise the question whether qualitative research has come to reflect and reinforce social forms of domination in Western consumer societies? There is surely not a simple answer to this provocative question, as qualitative research itself is very much a broad church. However, I allow myself to raise the question nonetheless, since I believe that it is almost always glossed over; perhaps even repressed under the banner of qualitative research being something particularly ethical, because it gives voice to subjective experience etc.

\section{Question 1: Ethical progressivism versus new ethical challenges}

This takes me directly to my three questions, the first of which I call "ethical progressivism versus new ethical challenges". With the late Steinar Kvale, I have published papers on some of the ethical challenges that emerge from the position of qualitative research today (e.g. Brinkmann \& Kvale, 2005). The biggest challenge might be related to the very idea of some but not all - qualitative researchers that qualitative research is ethically good in itself, or at least ethically superior to the hard, "uncaring" quantitative approaches of questionnaires and behavioral experiments. The idea that "we are ethically superior, because we are qualitative!" is widespread, and is, in my view, in fact a great obstacle to ethical research behavior. As Nietzsche once said: "there has never been a more dangerous ideology than the will to be good!" The first step to becoming moral may be realizing we are not.

The idea that qualitative research is ethically good in itself can be called qualitative ethicism (see also Hammersley, 1999). It is dangerous, because it blinds us to the societal conditions of what we do, as I referred to before, but also because it ignores those power relations that are 
inevitably in play in research activities, including those we set up as being empathetic, caring, respectful to subjectivity and so on. Interviewing, for example, is never in my view a symmetrical "method of friendship", as some have depicted it, operating in a zone of intimacy, free from issues of power and potential domination. Rather, interviewing is saturated with power. In general, there is an asymmetrical power relation in the interview, with the interviewer setting the agenda for the conversation. The interview is most often a one-way dialogue with the interviewer asking questions without providing answers. The interview is also an instrumental dialogue that is not a goal in itself (like a conversation with one's friends), but serves the researcher's ends of producing knowledge. And there is often a monopoly of interpretation on the side of the interviewer (these aspects are discussed in Brinkmann \& Kvale, 2005).

Taking into account the interviewee's options for counter-control - such as evading or not answering the questions - and the different counter powers of children and expert interview subjects, it still appears warranted to characterize qualitative research as saturated with more concealed forms of power than quantitative and experimental research. Interviewing may even involve what has been called commodification of the skills of "doing rapport", where the researcher engages in the affair of "faking friendship" in order to obtain knowledge (Duncombe \& Jessop, 2002). The British feminist qualitative researchers Jean Duncombe \& Julie Jessop have analysed instructions from qualitative method textbooks as evidence of the widespread, yet arguably unethical, tendency of researchers to commodify their trust, empathy and feelings. In one textbook, interviewers are thus encouraged to "manage their appearance, behaviour and self-presentation in such a way as to build rapport and trust with each individual respondent" (O'Connell Davidson \& Layder, 1994, pp. 122-3; my emphasis). And, in another well-known book, we are told that "trust is the foundation for acquiring the fullest, most accurate disclosure a respondent is able to make [...] In an effective interview, both researcher and respondent feel good, rewarded and satisfied by the process and the outcomes. The warm and caring researcher is on the way to achieving such effectiveness" (Glesne \& Peshkin, 1992, p. 79, p. 87).

The soft means - warmth, empathy and care - are used instrumentally to achieve hard ends, viz. effectiveness. Armed with good intentions and qualitative ethicism, qualitative researchers may nevertheless fail to be ethically prudent, I believe, if they fail to situate their means of knowledge production in power relations as these often reflect the wider cultural situation.

I thus conclude from the example of interviewing that new ethical challenges emerge when we do qualitative research in consumer society; challenges that may well be more difficult because they are more elusive and hidden, not least hidden under a widespread ethicism that paradoxically dodges some of the most important ethical questions in qualitative research.

\section{Question 2: Solid evidence versus subjective anecdotes}

Now, let me jump to the next question, which I call "solid evidence versus subjective anecdotes". I am going to discuss this in light of the evergreen we call "positivism". Back in the good old days of positivism and its critics, I mean when positivist sociology and psychology, for example, were under attack by philosophers such as Habermas and Gadamer in Germany, Peter Winch in Great Britain and, in the 1970s, by Ken Gergen and the like in the US, the discussion was a genuine epistemological one. Originally, the positivists wanted knowledge claims to be verifiable by human experience, which might not be such a bad idea after all... But positivism turned into physicalism, the idea that all sciences must employ the methods of the 
physical sciences and ultimately be reducible to the language of physics. Indeed a very bad idea...

But these matters were then discussed in terms of differing philosophies with arguments pro and contra. Today, however, especially in psychology, but also elsewhere, we see a resurgence of positivism, but this time not as a philosophical position, but rather as a bureaucratic approach to research funding, related to an emerging global audit culture. We might call this economical positivism to distinguish it from philosophical positivism, which is much better than its reputation. How can I make this claim? (the following is based on Kvale \& Brinkmann, 2008) Well, if you will allow me a brief intermezzo, there is little doubt that original positivist philosophy made a historical contribution, both to the social sciences and also to the arts: August Comte (1798-1857) founded both positivist philosophy and the science of sociology in the early nineteenth century. Positivist philosophy was a much needed reaction against religious dogma and metaphysical speculation and advocated a return to observable data. Significantly, this did not imply an exclusion of (what we now call) qualitative approaches. Quite the contrary. Emile Durkheim (for example) was one early sociologist who was influenced by positivism and who gave penetrating qualitative analyses of social phenomena. Positivism also had a wide influence on the arts of the 19th century, inspiring a move from mythological and aristocratic themes to a new realism, depicting in detail the lives of workers and the bourgeoisie. Flaubert's realistic descriptions of the life of Madame Bovary, for example, can be considered as a positivist novel, and impressionist paintings, sticking to the immediate sense impressions, in particular the sense data of pointillism, also drew inspiration from positivism. Michel Houllebecq is one contemporary French author who explicitly acknowledges his inspiration from Comte's positivism. Early positivism was also a political inspiration for feminism, and it was the feminist Harriet Martineau (sometimes called the first feminist sociologist) who translated Comte's Positive Philosophy into English.

All this is to say that we too often use positivism as a term of abuse without understanding its historical importance or its rational core. And, as Joel Michell (2003) has recently argued, there is little in classical positivism that is hostile to qualitative research. But today, with what I call economical positivism, we see a much more powerful exclusion of qualitative research, for example with reference to evidence hierarchies and the like. With a background in biomedicine, the Cochrane movement has developed an evidence hierarchy, which has placed randomized controlled experiments as "the gold standard", and expert opinion, as well as qualitative research, at the bottom level of evidence. These strict criteria of evidence may be adequate for some parts of biomedical research. However, when they are extrapolated to other forms of research, they too often result in a "politics of evidence" (Morse, 2006), where qualitative research in general becomes marginalized. The explorative, interactive, and case-based approach of many qualitative studies does not fit the logic of strictly controlled experimentation. The effect of the evidence-based practice movement on qualitative research has largely been to discredit qualitative research, hampering the acceptance of research proposals and the funding of qualitative research, and it has supported a methodological conservatism (Denzin and Giardina, 2006). The quantitative dogma of the evidence movement is today in line with a rationalization and bureaucratization of society, conceptualized as an "audit culture". It conforms to the all-pervasive economic performativity of consumer society, where everything that exists can be measured in money, or else is dismissed: "be operational (that is, commensurable) or disappear", as Lyotard (1984) put it in his famous book on the postmodern condition. 
The reaction of some qualitative researchers has been to go in the exact opposite direction of celebrating subjectivity against objective and intersubjective evidence, echoing Søren Kierkegaard (my compatriot) that "subjectivity is truth and truth is subjectivity". In qualitative research, we are not concerned with objective matters of fact, they claim, but with the personal, subjective, experiential aspects of life. Although there is much to learn from this response, I believe it too easily accepts the either-or question of solid evidence versus subjective anecdotes. Reducing qualitative research to subjectivity is deeply unfair in my view, and it misses the fact that on many reasonable interpretations of what it means to be objective, qualitative research can indeed attain objectivity. If being objective means reflecting the nature of the object researched, letting the object speak, or being adequate to the object investigated, qualitative research seems entirely capable of being objective (Kvale \& Brinkmann, 2008). For only qualitative research can throw light on qualitative features of the world. And, as I mentioned earlier, people in the natural sciences know this very well. Accepting the subjective as the only field of play for qualitative research is simply to buy into a false question that furthermore situates qualitative research too firmly in consumer society with its celebration of subjectivity: As they say - "the customer is always right"...

\section{Question 3: Method versus intuition}

My final question that follows from this is "method versus intuition". With this question I refer to the ongoing discussion between those, on one side, who argue that we need rigorous methods in qualitative research in order to be adequately scientific, and those on the other side, who argue that rigorous methods are detrimental to the creativity of qualitative research, and that we instead should rely on subjectivity, artistry and intuition. Norman Denzin is perhaps a spokesperson for the latter view.

In his recent book entitled Methodology: Who needs it? Martyn Hammersley (2011) has drawn a distinction between three different genres within the literature of methodology. He calls these methodology-as-technique, methodology-as-philosophy and methodology-as-autobiography. I believe that one central genre is lacking, which is the one I will advocate to balance between rigorous method and creative intuition. This is methodology-as-craftsmanship. I will return to this soon.

Staying with my reading of qualitative research in light of the cultural situation of consumer society, I will first raise the question, whether we today - with the call for methods and techniques in qualitative research - are witnessing a McDonaldization of qualitative research

\section{The McDonaldization of qualitative research}

Sociologist George Ritzer (2008) is famous for having coined the term McDonaldization to describe an array of significant aspects of modern consumer society. Ritzer continues the classical work of Max Weber, depicting the "rationalization" of society as a bureaucratic "iron cage", famously portrayed in the novels of Franz Kafka. Moving from industrial to consumer society means moving from the iron cage and into fast food restaurants such as McDonalds. In a recent analysis, Clive Nancarrow and co-workers (2005) from Great Britain have addressed qualitative marketing research specifically and argued that this kind of research has undergone a process of McDonaldization. I believe that qualitative research more broadly and globally stands in danger of falling into McDonaldization, when it becomes an industry that affects and is affected by consumer society. 
In his books on McDonaldization, Ritzer highlights four primary components that have been perfected at McDonald's restaurants, but which have spread throughout consumer society according to Ritzer:

The first component is efficiency, which means employing the best and least wasteful route toward one's goal. The current emphasis on methods in qualitative research, which can sometimes even be characterised as methodolatry, or a worship of methods, is in line with the call for efficiency, and the term 'method' originally comes from Greek and meant "a way to a goal". Methods are supposed to get us from A to B as fast and efficiently as possible. Nancarrow and co-workers (2005) argue in their article on the McDonaldization of market research that focus groups are employed to an increasing extent, because they are a fast and efficient way to obtain data.

The problem with efficiency is that imaginative and penetrating research demands time and patience. We cannot demand, when we do research, that everything should be geared toward minimising time. Proper field work may take months or even years, which is not unusual in social anthropology. If you want to know and understand other people, you need to spend time with them, but today it is the case that we, as qualitative researchers, are rather like Zygmunt Bauman's (1996) tourists, who visit others for a brief period of time (maybe just for one hour), take our snapshots (i.e. record the conversations), and then leave for the next destination. Interviewing is becoming the preferred choice in qualitative research, not because it is always the optimal way to answer one's research question, I believe, but because it appears to be less time consuming than ethnographic fieldwork, for example. If qualitative market research is leading the way for us, we may conjecture that even the individual interview will become less widely used in comparison with focus groups, as these are often even less expensive and faster in data collection.

The second component is calculability, signalling the audit culture that is part of McDonaldization. Initially, calculability sounds like it should be far away from qualitative concerns. However, anyone who has read qualitative research proposals will recognize this trope, for example when it is stated that " 30 people will be interviewed, 15 men and 15 women" and the like. Why 30 ? Why not 3 or 300 ? How can we know in advance how many participants we need? Such questions are often bypassed when qualitative researchers emulate the kind of calculability that may be a virtue in quantitative research.

The problem with calculability is first and foremost the fact that it sits uneasily with the emergent and imaginative processes of qualitative research. In general, when the goal is to know and understand other people, calculability will restrain the potentials of qualitative research.

The next component is predictability, defined by Ritzer as uniformity across settings and times. "Predictability" means that people will everywhere receive the same service and product every time they interact with McDonalds. Like calculability, predictability often goes directly against the promises of qualitative research to be inductive and flexible. The virtue of predictability is "no surprises!", but granting that this can be seen as a virtue in the fast food industry, it is more like a vice in qualitative research. Qualitative research is increasingly becoming standardised, witnessed for example in the enormous amount of technical "how to" books that tells you what to do, regardless of the subject matter, context and basic philosophical approach. Just as a Big Mac is the same all over the planet, interviewing others is often supposed to be a process that 
can be standardised, whether the interviewee is a single mother in Ghana or a senior citizen in Denmark.

The main problem of predictability is that qualitative research, which is interested in contextual experience and emergent meaning making, simply cannot be rendered predictable. We need qualitative research exactly when we can not keep controlled factors constant.

The final component is control, which, for Ritzer, refers to the non-human technology that speeds the operation, or, to put it in more negative terms, takes skills away from people. In qualitative research, there has been a growth in the number of research projects that employ CAQDAS - computer assisted qualitative data analysis software. This may increase the feeling of control when dealing with very large amounts of data, but there are also dangers associated with the outsourcing of central aspects of analysis to computer programs.

The problem of control by taking skills away from people thus concerns the fact that existing computer programs are well-adapted for coding strategies, for examples, whereas the many other forms of analysis, such as narrative and discursive analyses, figure less in the computerassisted programs for textual analysis. There is thus a danger that the ready availability of computer programs for coding can have the effect that coding (and such approaches as Grounded Theory) becomes a preferred short-cut to analysis, at the expense of a rich variety of modes of analyses.

As Nancarrow and co-workers conclude about the impact of McDonaldization on qualitative research:

Just as McWorld creates 'a common world taste around common logos, advertising slogans, stars, songs, brand names, jingles and trademarks' [...], the qualitative research world also seems to be moving towards a common world taste for an instantly recognisable and acceptable research method that can be deployed fast. (Nancarrow et al. 2005, p. 297).

\section{Qualitative research as a craft}

The antithesis to McDonaldization is craftsmanship, and I will end my talk today with addressing qualitative research as craftsmanship. If George Ritzer (2008) is the sociologist of McDonaldization, Richard Sennett is the sociologist and analyst of craftsmanship, especially in his recent book simply entitled The Craftsman (2008). It's a book that I cannot recommend enough. In previous works, Sennett has articulated a particularly influential critique of contemporary consumer culture and what he calls its 'flexible capitalism'. He has analyzed how this culture leads to a 'corrosion of character' in our workplaces and how it forces us to consider ourselves as consumers rather than citizens. His recent work on craftsmanship can be seen as a rather more constructive attempt to point to existential resources and moral practices that are still with us, but that we have forgotten in our times with our incessant focus on flexibility and the short-lived.

Craftsmanship, for Sennett, is not just a name for old production practices such as carpentry or masonry. It names, to quote his own words, "an enduring, basic human impulse, the desire to do a job well for its own sake." (Sennett, 2008, p. 9). Doing something well for its own sake has been forgotten as a basic human value in our instrumental approach to life, he claims, where most things that we do are stepping-stones to further success in the future. People who aspire to 
be good craftsmen today, Sennett says, are therefore often "depressed, ignored, or misunderstood by social institutions." (p. 145). They do not square with the reigning ethos of McDonaldization, so characteristic of our times.

What it means to do something well, according to the craftsman's form of life, is not a subjective issue, i.e., something that an isolated individual may decide for herself. Rather, as Sennett says, "craftsmanship focuses on objective standards, on the thing in itself." (Sennett, 2008, p. 9). There must thus be masters who set standards and train newcomers in the arts and practices of the craft, i.e., someone who inculcates the proper habits in apprentices (p. 54). Good skills, for a craftsman, are inseparable from ethics, since work skills involve such virtues as perseverance, loyalty, and commitment to standards that transcend an individual's perspective. First and foremost, the craftsman represents the special human condition of being engaged, and Sennett advocates the kind of modern pragmatism that "could be said to take on faith [Thomas] Jefferson's belief that learning to work well is the foundation of citizenship' (p. 290). This, it seems to me, is as far away from McDonaldization as one can get.

In the human and social sciences, we have had our own advocates of research as craftsmanship, most famously C. Wright Mills (1959). In the 50s, Mills depicted social research in general as "intellectual craftsmanship". In this light, mastery of the relevant methods and theories are important for the craft of social research, but should not become autonomous idols of scientific inquiry. Methods, Mills argued, "are like the language of the country you live in; it is nothing to brag about that you can speak it, but it is a disgrace and an inconvenience if you cannot" (p. 121). Instead of using methods mechanically (to live up to demands for efficiency, calculability, predictability and control), Mills believed in the power of the researcher-craftsperson herself to generate insightful research. Here is a famous quote from Mills:

Be a good craftsman: Avoid any rigid set of procedures. Above all, seek to develop and to use the sociological imagination. Avoid the fetishism of method and technique. Urge the rehabilitation of the unpretentious intellectual craftsman, and try to become such a craftsman yourself. Let every man be his own methodologist; let every man be his own theorist; let theory and method again become part of the practice of a craft (Mills, 1959, p. 224).

Recently, anthropologist Tim Ingold (2011) has advocated C. Wright Mills' plea for intellectual craftsmanship, destroying traditional divisions between "theory" and "method". We do not (or should not) begin social research with a theoretical agenda that is then operationalised into testable hypotheses through methods, Ingold argues. Rather, we should acknowledge, as he says, "that there is no division, in practice, between work and life. [An intellectual craft] is a practice that involves the whole person, continually drawing on past experience as it is projected into the future." (p. 240). We should never forget that we do qualitative research for purposes of living, and theories and methods are just some of the tools we employ in the process (others, I might add, are art and education).

The approach to qualitative research that I wish to advocate here is one that tries to avoid the dangers of "methodolatry" on the one hand, and a mysterious reliance on subjective intuition on the other. To mechanically follow certain prespecified methodological steps does not guarantee scientific truth, let alone interesting research. Rather than distrusting our ordinary human capacities for observing and communicating about our lives, and allocating understanding to specific methods instead, we should focus on the person of the researcher as 
the actual research instrument itself. This was expressed, for example, by anthropologist Jean Lave in the following interview sequence, where Steinar Kvale (SK) acts as interviewer:

SK: Is there an anthropological method? If yes, what is an anthropological method?

JL: I think it is complete nonsense to say that we have a method. First of all I don't think that anyone should have $a$ method. But in the sense that there are "instruments" that characterise the "methods" of different disciplines - sociological surveys, questionnaire methods, in psychology various kinds of tests and also experiments - there are some very specific technical ways of inquiring into the world. Anthropologists refuse to take those as proper ways to study human being. I think the most general view is that the only instrument that is sufficiently complex to comprehend and learn about human existence is another human. And so what you use is your own life and your own experience in the world (Lave \& Kvale, 1995, p. 220).

I would like to add that after having written an international bestseller on the method of interviewing, and having read countless doctoral dissertations based on interviewing as well as numerous research proposals, Steinar Kvale came to the conclusion - toward the end of his life - that there is a negative correlation between the number of pages devoted to methodology and the quality of a manuscript that communicates qualitative research. The more methodology, the less valuable the contribution, was his analysis. "Why so", I asked him, when he revealed this surprisingly negative attitude toward methodology. Because, he answered, those who have discovered something novel and important through their studies will focus on what is new and exciting, whereas those who have not really found anything of interest can always fill their manuscript with sections on methodology. It is no coincidence that significant analysts of our time, such as Richard Sennett who does in fact use qualitative interviews quite extensively, does not in general have method sections in his books and papers. This may be at the expense of efficiency, calculability, predictability and control, but it is - at least in this and more than a few other cases - conducive to high quality research that not only lives up to the standards of the craft, but constantly pushes these further.

\section{Conclusion}

In conclusion, I should say that my attempt at understanding the nature of qualitative research as currently practiced by reading it in light of the cultural situation, is obviously not meant to render all qualitative research invalid. Every kind of human activity is situated somewhere, at a given point in time, but I believe that we, as a community of qualitative researchers, are not sufficiently alert to the challenges that arise from the society of which we are a part. Our response to these challenges, arguing that we are particularly ethical because we are qualitative, and that we are subjective and intuitive, actually just reinforces some of the pitfalls of consumer society with its individualising tendencies. My suggestion instead is that we rethink qualitative research as a craft. For surely and sadly, the main impact of qualitative research on modern society does not in general represent craftsmanship, but rather McDonaldization: it's quick, dirty and not very satisfying.

Thank you for your attention!

\section{References}

Atkinson, P. and Silverman, D. (1997). Kundera's Immortality: The interview society and the invention of the self. Qualitative Inquiry, 3, 304-325. 
Bauman, Z. (1996). From pilgrim to tourist - or a short history of identity. In S. Hall \& P. du Gay (Eds.) Questions of Cultural Identity. London: Sage.

Brinkmann, S. \& Kvale, S. (2005). Confronting the ethics of qualitative research. Journal of Constructivist Psychology, 18, 157-181.

Denzin, N.K \& Giardina, M.D (Eds.) (2006). Qualitative Inquiry and the Conservative Challenge. Walnut Creek, CA: Left Coast Press.

Duncombe, J. \& Jessop, J. (2002) 'Doing Rapport' and the Ethics of 'Faking Friendship'. In M. Mauthner, M. Birch, J. Jessop and T. Miller (Eds). Ethics in Qualitative Research. London: Sage.

Giddens, A. (1991). Modernity and Self-Identity. Cambridge: Polity.

Glesne, C., \& Peshkin, A. (1992). Becoming Qualitative Researchers: An Introduction. White Plains, NY: Longman.

Hammersley, M. (1999). Some reflections on the current state of qualitative research. Research Intelligence, 70: 16-18

Hammersley, M. (2011). Methodology: Who Needs It? London: Sage.

Honneth, A. (2004). Organized self-realization. European Journal of Social Theory, 7, 463-478.

Illouz, E. (2007). Cold Intimacies: The Making of Emotional Capitalism. Cambridge: Polity.

Imms, M. \& Ereaut, G. (2002). An Introduction to Qualitative Market Research. London: Sage.

Ingold, T. (2011). Being Alive: Essays on Movement, Knowledge and Description. London: Routledge.

Kvale, S. \& Brinkmann, S. (2008). InterViews: Learning the Craft of Qualitative Research Interviewing. (2nd ed.). Thousand Oaks, CA: Sage.

Lave, J., \& Kvale, S. (1995). What is anthropological research? An interview with Jean Lave by Steinar Kvale. Qualitative Studies in Education, 8, 219-228.

Lyotard, J. F. (1984). The Postmodern Condition: A Report on Knowledge. Manchester, UK: Manchester University Press.

Michell, J. (2003). The Quantitative Imperative: Positivism, Naïve Realism and the Place of Qualitative Methods in Psychology. Theory \& Psychology, 13, 5-31.

Mills, C. W. (1959). The Sociological Imagination. (This edition 2000). Oxford: Oxford University Press.

Morse, J. M. (2006). The Politics of Evidence. In N.K. Denzin \& M.D. Giardina (Eds.), Qualitative Inquiry and the Conservative Challenge. Walnut Creek, CA: Left Coast Press. 
Nancarrow, C., Vir, J. \& Barker, A. (2005). Ritzer's McDonaldization and applied qualitative marketing research. Qualitative Market Research, 8, 296-311.

O'Connell Davidson, J. \& Layder, D. (1994). Methods, Sex and Madness. London: Routledge

Paterson, M. (2006). Consumption and Everyday Life. London: Routledge.

Ritzer, G. (2008). The McDonaldization of Society. (5 ${ }^{\text {th }}$ ed.). Thousand Oaks, CA: Pine Forge.

Rose, N. (1999). Governing the Soul: The Shaping of the Private Self. (2nd. ed.). London: Free Association Books

Schulze, G. (1992). Die Erlebnisgesellschaft. Frankfurt: Campus.

Sennett, R. (2008). The Craftsman. New Haven: Yale University Press.

Author

Svend Brinkmann is a professor of psychology at the University of Aalborg, Denmark. Email: svendb@hum.aau.dk 